\title{
Een halve eeuw regulering van de financiële sector: observaties en enkele conclusies
}

\author{
Voorpublicatie
}

\author{
Prof. mr.drs. C.M. Grundmann-van de Krol*
}

\begin{abstract}
De auteur schetst de ontwikkelingen van het nationale en Europese financieel toezichtrecht vanaf de periode dat dit rechtsgebied aan belang en omvang heeft gewonnen. Zij beschrijft de in bet verleden ontstane bouwstenen (doelstellingen), basisregels en reguleringsarchitectuur die naar haar oordeel nog steeds richtinggevend zijn bij het verder reguleren van diensten, producten en nieuwe markten. Aandacht wordt besteed aan het steeds verder uiteenlopen van de crosssectorale Wft en de sectorale Europese.
\end{abstract}

\section{Introductie}

Bij het afronden van een nieuwe druk van Deel I Koersen door de Wet op het financieel toezicht die betrekking heeft op nationale en Europese aspecten van de regulering van de financiële sector en het toezicht op en de handhaving daarvan, kwam de gedachte op om het boek af te sluiten met enkele reflecterende observaties en conclusies. Deze waren ingegeven door de vraag wat er vanuit een helikopterperspectief bezien is veranderd sinds de regulering van de financiële sector circa een halve eeuw geleden haar intrede deed in de nationale wetgeving en door de Europese regulering op dat terrein. Het onderstaande is een voorpublicatie waarmee de nieuwe druk is afgesloten.

\section{Heden: een momentopname}

De Europese ontwikkelingen die in dit boek zijn geschetst, hebben ertoe geleid dat het huidige nationale financiële toezichtrecht zoals dat is omgezet in met name de Wet op het financieel toezicht (Wft) in combinatie met de van toepassing zijnde Europese verordeningen de facto het product is geworden van Europese regelgeving. De drie sectorale European Supervisory Authorities (ESA's) spelen in de huidige Europese regelgeving een relatief grote rol vanwege het ontwikkelen van ontwerpen van uitvoeringsregels op het tweede regelgevingsniveau, het vaststellen van soft law en het interactieve single rule

Prof. mr. drs. C.M. Grundmann-van de Krol is emeritus hoogleraar effectenrecht (in het bijzonder onderneming en financiële markten), Radboud Universiteit Nijmegen. book, maar ook vanwege hun interventiebevoegdheid door producten en diensten tijdelijk te beperken of te verbieden.

Niet minder belangrijk is dat de (politieke) weg is vrijgemaakt voor het vaststellen van steeds meer rechtstreeks werkende verordeningen die uiteraard zorgen voor maximumharmonisatie. In het streven naar betere regelgeving had de Europese Commissie (EC) al in 2007 gewezen op het feit dat de doelstellingen van rechtsvoorschriften niet ten volle worden gerealiseerd wanneer deze voorschriften niet correct worden toegepast en gehandhaafd. Dit zou kunnen worden verbeterd om, indien mogelijk, verordeningen vast te stellen en dat is sindsdien ook steeds meer het geval geworden. De keuze voor het opstellen van rechtstreeks werkende verordeningen hebben gezorgd voor een 'ontlasting' van de nationale wetgever van de lidstaten. Zij kunnen en moeten volstaan met de implementatie van slechts die lidstaatopdrachten of lidstaatopties die een Europese verordening bevat. Het betreft met name de verplichting tot aanwijzing van een bevoegde nationale autoriteit uitgerust met een arsenaal aan in de verordening vastgelegde toezichten handhavingsinstrumenten in combinatie met verplichtingen om met elkaar in Europees verband samen te werken. Daarbij is tevens, nadat in 2011 het Europees Systeem voor Financieel Toezicht (ESFS) en in 2014 de Bankenunie werd opgericht, een tendens te bespeuren om het toezicht en de handhaving al dan niet gedeeltelijk over te hevelen van nationaal toezicht naar centraal toezicht door een van de drie ESA's respectievelijk de Europese Centrale Bank (ECB). Een dergelijke europeanisering van toezicht ontlast de nationale toezichthouders zoals de europeanisering van de materiële regels de nationale wetgevers heeft ontlast van implementatiezorgen. Dit alles maakt dat als een soort communicerende vaten de Wft aan omvang en materiële normen afneemt naarmate meer Europese regels worden gegoten in verordeningen en naarmate meer centraal Europees toezicht wordt gerealiseerd.

Het adagium dat 'eenieder geacht wordt de wet te kennen', was en is in de praktijk wat betreft de cross-sectorale Wft 'problematisch'. Voor het Europese financiële toezichtrecht met 


\section{Maandblad}

Ondernemingsrecht

de bijbehorende uitvoeringsmaatregelen en Europese jurisprudentie is het in de praktijk inmiddels ook een bijna onhoudbare aanname geworden. Weliswaar verlicht de Europese sectorale opzet het vinden van de weg, maar anderzijds verzwaart het ook door de soms grote hoeveelheid uitvoeringsregels. De laatste jaren laten zien dat de gelaagde structuur op het niveau van uitvoeringsregels aangevuld met ESA-soft law die (meer) duidelijkheid moeten scheppen over de op het eerste niveau vastgestelde Europese regels, door het grote aantal en de omvang daarvan zodanig is geworden dat het moeite kost om niet alleen de toepasselijke regels te 'ontdekken' maar deze ook juist te interpreteren bij gebreke aan veelal een uitgebreide toelichting. Zo zijn ter uitvoering van de antimisbruikbepalingen en de regels voor beleggingsondernemingen zestien respectievelijk meer dan vijftig gedelegeerde uitvoeringsverordeningen opgesteld. Dat is zonder de aanvullende ESAsoft law in aanmerking te nemen die uitwerken als min of meer 'harde' regels zeker wat betreft de talloze richtsnoeren die op het ESA-niveau zijn aangemerkt als niet bindend maar door het comply or explain-systeem op het nationale niveau bindend worden indien en zodra de nationale toezichthouder te kennen geeft deze 'to comply' hetgeen meestal het geval is. Door het geven van richtsnoeren en aanbevelingen met hun visie op en de uitleg van de Europese materiële regels beïnvloeden de ESA's het nationale recht. Bovendien zorgen de snelheid en frequentie waarop de desbetreffende regels worden gewijzigd of aangevuld er voor dat min of meer voortdurend een 'actualiteitscheck' moet worden uitgevoerd. Hulpmiddel daarbij is wel - en het bestaan daarvan illustreert impliciet dat zonder een hulpmiddel het bijna 'ondoenlijk' is geworden als een soort draad van Ariadne het sectorale 'interactive single rulebook' die door de ESA's voor elk van ieders werkterrein is opgesteld en wordt bijgehouden.

\section{Reguleringsmotoren}

De motoren die hebben gezorgd voor Nederlandse en Europese regelgeving waren nationale en mondiale financiële crises en de globalisering waardoor een grote vervlechting is ontstaan in de internationale financiële sector. Nationale en grensoverschrijdende crises hebben hun stempel gedrukt op het onderwerpen van diverse activiteiten aan regelgeving en tevens een soort blauwdruk geschapen over welke beginselen leidend zijn bij het reguleren van nieuwe activiteiten. Het ontstaan van het Nederlandse financieel toezichtrecht inhoudend regels voor het optreden op de Nederlandse financiële markten, gaat terug tot de zestiende eeuw en was voor een groot deel ingegeven door een nationale crisis. De aanleiding voor het stellen van regels was meestal een bepaalde misstand of een financiële crisis. Een Nederlands voorbeeld uit de hoogtijdagen van de VOC was het Plakkaat uit 1610 op grond waarvan 'blanco verkoop' (shortselling) van VOC-aandelen werd verboden om speculatie tegen te gaan. De argumentatie voor het ingrijpen was dat de rustige belegging van spaarders, weduwen en wezen niet mocht worden verstoord door manipulaties van derden. Voorbeelden van financiële crises van recentere datum - voordat het Europese toezichtrecht zijn intrede deed in de nationa- le wetgeving - die leidden tot het nemen van diverse wettelijke maatregelen om 'ordening' aan te brengen in de voor de economie zo belangrijke financiële markten waren de vertrouwenscrisis in 1914 ten aanzien van bankbiljetten en de tegelijkertijd plaatsvindende beurskrach van de Amsterdamse aandelenbeurs, de deconfiture van het emissiehuis Mendelssohn en Co in 1940 en het faillissement van bank Texeira de Mattos in 1966. Het faillissement in 1995 van de Nederlandse verzekeringsmaatschappij Vie d'Or leidde niet alleen tot nieuwe (strengere) regels, maar ook tot belangrijke jurisprudentie van de Hoge Raad. Het Vie d'Or-arrest stond aan de basis om de aansprakelijkheid van de nationale toezichthouders te beperken teneinde een 'toezichthoudersdilemma' te voorkomen dan wel te reduceren: het dilemma dat een toezichthouder in zijn toezicht en handhaving enerzijds te actief is waardoor de onder toezicht staande instelling schade zou kunnen worden berokkend en anderzijds te weinig actief is waardoor derden schade zouden kunnen lijden met het risico van aansprakelijkstelling van de toezichthouder door de gedupeerden.

Enkele voorbeelden van niet uitsluitend nationale crises die de aanzet gaven voor Europese regelgeving en daarmee ook voor de nationale wetgeving van de lidstaten zijn het faillissement in 1991 van de Bank for Credit and Commerce International (BCCI) met meer dan vierhonderd bijkantoren in 78 landen. Door de implementatie van de BCCI-richtlijn werd het bedrijfseconomisch toezicht in de nationale lidstaten verscherpt. Ook de ondergang van de bank Barings in het Verenigd Koninkrijk in 1995, het boekhoudschandaal van het energiebedrijf Enron in de Verenigde Staten gevolgd door het faillissement van Enron in 2001 hadden direct dan wel indirect gevolgen voor nationale en Europese regelgeving. De stagnerende huizenmarkt in de Verenigde Staten in de zomer van 2007 onder meer veroorzaakt doordat obligaties als 'verpakte gebundelde hypotheken' in het laagste segment ('subprime') in een razend tempo minder waard werden, resulteerde in de ineenstorting van de investeringsbank Lehman Brothers, met wereldwijde desastreuze gevolgen. De oorzaken van de problemen lagen echter dieper en veel verder in het verleden. 'Uitbundige' bestedingen in de Angelsaksische wereld veroorzaakten tekorten op de betalingsbalansen en een overmatige schuldfinanciering in de private sector. De crisis in het subprime segment was in feite een uitvloeisel van deze overmatige schuldfinanciering. Dat de desastreuze gevolgen op wereldschaal pijnlijk zichtbaar en gevoeld werden, was toe te schrijven aan een voortdurende en toenemende globalisering, mede mogelijk gemaakt door nieuwe informatie- en communicatietechnieken en digitalisering, resulterend in onderlinge afhankelijkheid van de financiële markten. Teneinde in de toekomst een dergelijke mondiale financiële crisis te voorkomen dan wel de gevolgen daarvan zo veel mogelijk te verminderen werd wederom bestaande Europese regelgeving aangescherpt en nieuwe regelgeving opgesteld. 


\section{Bouwstenen: doelstellingen}

Op de aanvankelijk aftastende Europese periode die werd gekenmerkt door het vaststellen van richtlijnen met een minimumharmonisatie die terug te vinden waren in de nationale toezichtregelgeving van de lidstaten, volgde een periode waarin steeds vaker richtlijnen werden opgesteld met een grote mate van harmonisatie en deed duale regelgeving op het eerste niveau haar intrede: een combinatie van zowel een richtlijn om te zetten in de nationale wetgeving van de lidstaten als een rechtstreeks werkende verordening ter regulering van een bepaalde activiteit of terrein, zoals de MAD en de MAR met regels om markmisbruik tegen te gaan, de MiFID II en de MiFIR met regels voor beleggingsondernemingen en de CRD en de CRR met kapitaalvereisten voor banken en beleggingsondernemingen.

Terugkijkend naar het begin dat het Europese toezichtrecht zijn intrede deed in het Nederlandse recht en tegelijkertijd kijkend naar het huidige Europese toezichtrecht en de al gepubliceerde nieuwe initiatieven, valt op dat de doelstellingen voor regulering en uitbreiding daarvan grosso modo in stand zijn gebleven. Deze waren en zijn het scheppen van een gelijk speelveld (level playing field). Enerzijds door het opheffen van belemmeringen voor het vrije verkeer van personen, diensten en kapitaal tussen de lidstaten teneinde de gemeenschappelijke financiële EU-markt te maken tot een geïntegreerde markt die met andere niet-Europese financiële markten zou kunnen concurreren. Anderzijds het besef dat in een geïntegreerde financiële markt falend nationaal toezicht ook effecten heeft buiten de grenzen van die ene lidstaat en dat zowel nationale als Europese toezichthouders de beschikking moeten krijgen over de juiste instrumenten, vaardigheden en bevoegdheden om toezicht te kunnen houden. Maar ook de bescherming van beleggers en consumenten en het waarborgen van de stabiliteit van het financiële stelsel zijn sinds een kwart eeuw twee belangrijke 'paraplu'-doelstellingen geworden voor het opstellen van regels en nadien het aanscherpen van bestaande regels. Beide doelstellingen zijn in het verleden én in het heden een kapstok of paraplu ter legitimatie van de aanwezig geachte noodzaak voor het opstellen van diverse soorten regels. Indien beleggers geen vertrouwen hebben en houden in 'eerlijke' en goed functionerende kapitaalmarkten zal dit ten koste gaan van investeringen om de economie draaiend te houden. De gedachte hierbij was (en is nog steeds) dat goed functionerende financiële markten voor een groot deel afhankelijk zijn van het vertrouwen dat (potentiële) beleggers en consumenten in die markten stellen en dat dit vertrouwen niet alleen berust op de aan hen te bieden 'waarborg' dat zij worden beschermd tegen ongeoorloofd gebruik van voorwetenschap door ingewijden, maar ook door uitgevende instellingen te onderwerpen aan transparantie-eisen en door tussenpersonen een zekere zorgplicht op te leggen jegens niet-professionele beleggers opdat de informatie-asymmetrie tussen aanbieders van beleggingsproducten en de afnemers daarvan zo gering mogelijk is of zelfs wordt opgeheven. Vertrouwen in de financiële sector als geheel is zo eminent dat ook is voorzien in de bevoegdheid van de nationale toezichthouders om het grote publiek te waarschuwen tegen diegenen die dit vertrouwen schaden door inbreuk te maken op de desbetreffende regels.

\section{Basisregels: grondbeginselen}

Gebleven zijn ook de Europese basisregels die worden toegepast bij het reguleren van nieuwe terreinen en de actoren die op die terreinen actief zijn. Al tijdens de eerste inspanningen in de jaren zeventig van de vorige eeuw om de financiële systemen van de lidstaten te integreren in de Europese financiële markt is een stramien ontwikkeld van basisregels ter regulering van entiteiten en producten. Deze eerste inspanningen waren gebaseerd op de beginselen van vrijheid van vestiging en vrije dienstverrichting: het scheppen van een 'eerlijke' concurrentie en de bescherming van diegenen die financiële diensten of producten afnemen. Alleen dan werd wetgeving opgesteld indien coördinatie noodzakelijk werd geacht om deze belemmeringen op te heffen. Vastgelegd was dat de liberalisatie van de door banken en verzekeringsmaatschappijen verrichte diensten waarmee kapitaalverplaatsingen gepaard gaan, 'moest worden verwezenlijkt in overeenstemming met de geleidelijke liberalisatie van het kapitaalverkeer'. De Europese Raad kreeg een mandaat om een programma vast te stellen voor de opheffing van bestaande beperkingen. Met het oog op de uitvoering daarvan stelde de Raad tussen 1973 en 1979 onder meer richtlijnen vast ter regulering van het bankwezen, het verzekeringswezen en het effectenwezen: een Europese sectorale aanpak die tot nu toe grotendeels is gehandhaafd. Voor de eerste twee sectoren ging het om het reguleren van het bancaire bedrijf en het verzekeringsbedrijf. De regulering van het effectenbedrijf was vooralsnog gericht op de handel ter beurze. Deze eerste sectorale Europese richtlijnen werden tot de totstandkoming van de cross-sectorale Wft omgezet in sectorale toezichtwetten met aanvankelijk ook drie sectorale toezichthoudende entiteiten: voor het bankwezen De Nederlandsche Bank, voor het verzekeringswezen de Pensioen- en Verzekeringskamer en voor het effectenwezen werd de Stichting toezicht effectenverkeer opgericht (thans Autoriteit Financiële Markten (AFM)).

De contouren van de Europese basisbeginselen die thans nog ten grondslag liggen aan het verder reguleren van andere en nieuwe terreinen binnen de financiële sector lieten zich toen al zien. Ondernemingen die actief waren op de financiële markt - in casu banken en verzekeraars - werden onderworpen aan een vergunningplicht. Een vergunning kon uitsluitend worden verkregen indien werd voldaan aan het beschikken over een voldoende minimum aan eigen (afgescheiden) vermogen en over betrouwbare beleidsbepalers in het bezit van de vereiste ervaring om beleidsfuncties uit te oefenen. Een vergunningaanvraag diende vergezeld te gaan van een programma van werkzaamheden waarin met name de aard van de beoogde verrichtingen alsmede de organisatiestructuur van de instelling moesten worden vermeld. Om toezicht te kunnen houden op de werkzaamheden van die instellingen waarvan het werkterrein zich tot een of meer andere lidstaten uitstrekte, gold een verplichting tot nauwe samenwerking tussen de bevoegde au- 


\section{Maandblad}

Ondernemingsrecht

toriteiten van de betrokken lidstaten, met name in het elkaar verstrekken van gegevens. Daarbij was bepaald dat alle personen die werkzaam zijn of werkzaam zijn geweest bij de bevoegde autoriteiten, gebonden zijn aan een beroepsgeheim: vertrouwelijke inlichtingen die zij beroepshalve ontvingen, mochten aan geen enkele persoon of autoriteit bekend worden gemaakt tenzij krachtens wettelijke voorschrift en op in het kader van de samenwerking ontvangen informatie was het beroepsgeheim eveneens van toepassing. Wel mochten ontvangen inlichtingen worden gebruikt voor het onderzoek naar de toelatingseisen en om de controle te vergemakkelijken op de liquiditeit en de solvabiliteit van de betrokken instellingen of wanneer tegen een besluit van de bevoegde autoriteit een administratief beroep of beroep op de rechter werd ingesteld. Ook toen werd het al verboden dat de lidstaten op bijkantoren van een instelling uit een derde land bepalingen toepassen die een gunstiger behandeling tot gevolg zou hebben dan die voor bijkantoren van een instelling met een hoofdkantoor in een lidstaat. In de eerste richtlijnen ter regulering van het effectenbedrijf werden eisen gesteld voor de toelating van effecten tot een effectenbeurs, eisen waaraan een beursprospectus moest voldoen en eisen inzake de periodieke informatieverschaffing door beursgenoteerde instellingen. Deze informatie-eisen werden later uitgebreid voor aanbiedingen aan het publiek van niet beursgenoteerde effecten en van andere financiële producten dan effecten. Het doel van de informatieverstrekking over een aangeboden dienst of beleggingsproduct was en is het aan de afnemers verschaffen van voldoende informatie om een doordachte beslissing te kunnen nemen.

Deze Europese basisregels - samen te vatten als de Europese regelgevingsarchitectuur - zijn een telkens terugkerend stramien geworden bij elk onderdeel van de financiële sector die werd en wordt gereguleerd, zoals recent de crowdfundingmarkt door de Crowdfundingverordening en binnenkort de cryptomarkt door de toekomstige MiCA-verordening. Zij zijn voor zover mogelijk afgestemd op de aard en omvang van de werkzaamheden van de betrokken categorie entiteiten en de economische relevantie van hun werkzaamheden. De te reguleren entiteit zal in het kader van de bescherming van de 'afnemers' van de dienst of het product moeten voldoen aan enerzijds eisen inzake betrouwbaarheid en geschiktheid, bedrijfsvoering, prudentiële waarborgen en vermogensscheiding als middel om de afnemers een zekere financiële zekerheid te bieden en anderzijds aan informatieverstrekking over tal van kenmerken van het product of de dienst. Wat betreft de basisregel van informatieverstrekking is wel een kentering te bespeuren in de omvang en gedetailleerdheid daarvan. Mede naar aanleiding van empirisch onderzoek is inmiddels vastgesteld dat het informatieparadigma een beperkte (beleggersbeschermende) werking heeft zodra het verplichte aanbod aan informatie het stadium van een 'overaanbod' bereikt. Op basis daarvan en gelet op enkele Europese actieplannen is de kans groot dat er op Europees en nationaal niveau wordt overgegaan tot het terugdringen van een overdaad aan informatieverplichtingen voor aanbieders van diensten en beleggingsproducten. Daarmee blijft de basisregel wel in stand maar wordt deze, terecht, onderworpen aan een effectiviteitstoets.

Uiteraard zijn de hiervoor genoemde basisregels niet limitatief en evenmin in graniet gebeiteld. Ik acht het niet uitgesloten dat aan de bestaande basisregels in de nabije toekomst een basisregel wordt toegevoegd wanneer het gaat om de relatie met derde landen en regulering van nieuwe diensten of aanpassing van de huidige regels. Mede door het vertrek van het Verenigd Koninkrijk uit de EU verwacht ik dat de toepassing van de 'initiative test' een zodanig ruimer bereik krijgt dat het een nieuwe basisregel wordt in het Europese derdelandenbeleid. De 'initiative test' is thans al geregeld in de MiFID II en zal worden geregeld in de nog aanhangige MiCA-verordening. Door toepassing van de 'initiative test' worden entiteiten uit een derde land, zoals het Verenigd Koninkrijk, 'geaccommodeerd' doordat op dergelijke entiteiten de Europese regels in beginsel niet van toepassing zijn indien zij uitsluitend op initiatief van een in de EU gevestigde (rechts)persoon worden benaderd om diensten te verlenen en zich strikt onthouden van het promoten van hun diensten.

\section{Nieuwe doelstellingen en 'aanjagers' van nieuwe Europese regelgeving}

Beleggersbescherming en de stabiliteit van het financiële stelsel zijn nog steeds leidende doelstellingen en daardoor inmiddels als vanzelfsprekend aanvaarde drijfveren voor herziening van oude regels en opstellen van nieuwe regels. In aanvulling op die doelstellingen is een relatief nieuwe doelstelling en in het kielzog daarvan een drijfveer om in actie te komen is de wereldwijde klimaatcrisis die zich decennia lang afspeelt en verergert en waarvoor al lang was gewaarschuwd. Ten langen leste is ingezien dat ook deze crisis moet worden aangepakt zij het met ook een 'knipoog' naar de nationale en internationale economie. De klimaatcrisis is thans onderdeel geworden van recente Europese regelgeving voor de financiële sector. Om de wereldwijde klimaatcrisis op zijn minst te stoppen ter voorkoming van verdere klimaatveranderingen die niet alleen de biodiversiteit maar ook de volksgezondheid schaden is voorzien in een pakket van regelgeving voor een duurzame (financiële) samenleving met het ambitieuze streven dat de EU als een van de eersten klimaatneutraal wordt. De 'makers' en aanbieders van beleggingsproducten worden verplicht informatie te verstrekken of, en zo ja, in welke mate hun producten bijdragen aan duurzaamheid om beleggers te bewegen met name te investeren in duurzame beleggingsproducten. Op basis van deze informatie zouden beleggers en afnemers in staat moeten zijn producten en diensten te vergelijken en vervolgens een voor hen verantwoorde beslissing te nemen. Een mondiale gezondheidscrisis ontstaan door het COVID-19-virus en diverse varianten daarop hebben in allerijl gezorgd voor versoepelingen van de regelgeving om de economische gevolgen daarvan te 'verzachten'. De klimaatcrisis en de gezondheidscrisis hebben laten zien dat deze crises, hoewel van een geheel andere aard, de 'gewone' internationale financiële crises verre overstijgen in termen van financiële gevolgen en hardnekkigheid om deze te keren en in 


\section{Maandblad}

Ondernemingsrecht

het gunstigste geval te overwinnen. Daarentegen zal de Wirecard-boekhoudfraude die enigszins is te vergelijken met de Enron-affaire, zeer waarschijnlijk weer leiden tot een verscherping van de transparantieregels en het toezicht op en de handhaving daarvan. Het is als het ware een voortdurende golfbeweging: de slinger gaat vooruit maar ook weer terug, overigens niet steeds in gelijke mate vooruit of achteruit.

Een ander - niet aangedreven door internationale financiële crises, klimaatcrisis of gezondheidscrisis - motorblok voor regulering zijn innovatieve en technologische ontwikkelingen die door de financiële (diensten)sector zijn omarmd en nieuwe soorten financiële producten, diensten en markten hebben doen ontstaan. Steeds meer (digitale) diensten werden en worden onderworpen aan regulering, soms eerst op nationaal niveau en vervolgens op Europees niveau om te voorkomen dat bij grensoverschrijdende dienstverlening nationale regels een vrij verkeer van goederen en diensten belemmeren of zelfs in de weg staan én om uiteindelijk te komen tot een innovatieve eengemaakte EU-markt met zeer waarschijnlijk binnen niet al te lange tijd de invoering van een digitale euro waarover de nationale centrale banken en de ECB gedachten en consequenties hebben neergelegd in diverse studies. Ook vanuit het oogpunt van beleggersbescherming waren in de visie van de Europese wetgever specifieke regels nodig indien, bijvoorbeeld, gebruik wordt gemaakt van algoritmische handel of 'bigh frequency trading' (flitshandel), nieuwe technieken die slechts voor een handvol personen te doorgronden zijn. Deze technieken kunnen ook negatieve ('oneerlijke') concurrentiegevolgen hebben aangezien zij niet voor iedere handelaar zijn weggelegd vanwege de daaraan verbonden hoge kosten. Juist bij de innovatieve en technologische ontwikkelingen kan het ontwikkelingsproces relatief snel gaan waardoor EU-actieplannen elkaar in een snel tempo opvolgen soms voordat een vorig plan geheel is uitgevoerd. Onderdeel van technologische ontwikkelingen is ook dat er een steeds grotere aandacht is gekomen om zich te wapenen tegen cybercriminaliteit. Versterking van cyberbeveiliging zal op Europees niveau verplicht worden gesteld door middel van het opzetten van veerkrachtige ICT-systemen en ICT-instrumenten die de invloed van ICT-risico's tot een minimum zouden moeten beperken. Door innovatieve technologische ontwikkelingen en de vooruitgang op het gebied van informatie- en communicatietechnologie, ontstonden ook complexe gestructureerde financiële beleggingsproducten die, zodra die schadelijk worden geacht voor met name de niet-professionele belegger, worden geweerd door gebruikmaking van de bevoegdheid tot productinterventie, zoals recent wat Nederland betreft met betrekking tot 'turbo's'. Het is een vorm van balanceren dan wel laveren tussen stimulering van innovatie en inperking daarvan ter bescherming van beleggers. Ook ten aanzien van deze onderwerpen is het door de internationalisering en globalisering van financiële markten geen nationale kwestie meer.

\section{Het Europese sectorale model en het Nederlandse cross-sectorale model: moeizame partners}

Hoewel er ook Europese regels tot stand zijn gekomen die sectoroverstijgende kenmerken hebben, zoals de PRIIP's-verordening en de PEPP-verordening met informatievereisten ongeacht welke sectoraal gereguleerde entiteit de desbetreffende PRIIP of PEPP aanbiedt, zijn de meeste Europese regels nog steeds grotendeels sectoraal. Dat geldt echter niet zodra Europese sectorale richtlijnen de weg naar Den Haag afleggen om omgezet te worden in de Wft. Daar komen de drie sectorale Europese stroomgebieden in een cross-sectorale Wft-delta bijeen waar geen waterscheiding meer is. De sectorale Europese regels worden getransformeerd in nationale cross-sectorale regels met de onvermijdelijke sectorale uitzonderingen. Cross-sectorale regels zonder een cross-sectorale toezichthouder ('one peak') naast een andere peak voor de monetaire taken (DNB), een theoretische mogelijkheid die zou hebben moeten leiden tot het samengaan van de AFM en DNB met achterlating bij DNB van haar monetaire taken. Het zou een politiek onbegaanbare weg zijn geweest en niet voor niets is dan ook gekozen om de cross-sectorale regels in tweeën te delen in een prudentieel deel en een gedragsdeel met elk een eigen toezichthouder: het 'twin peaks'-model zoals dat indertijd in verschillen andere landen, ook in niet EU-landen, werd ingevoerd en uitgeprobeerd. Aan het 'zuivere' twin peaks-model heeft de Wft-wetgever later wel concessies moeten doen, enerzijds 'gedwongen' door sectorale Europese richtlijnen en anderzijds door een 'incident' zoals het faillissement van de DSB-Bank. Diverse samenwerkingsbepalingen tussen de twee nationale toezichthouders moesten worden opgesteld. Ingevoerd werd zelfs de figuur van de bindende aanbeveling van de niet-vergunningverlenende toezichthouder aan de vergunningverlenende toezichthouder in geschiktheids- en betrouwbaarheidskwesties die onderdeel uitmaken van ieders toezichtdomein. Dat laatste is meer dan slechts een concessie aan het 'twin peaks'-model. Het wordt algemeen gezien als een 'echte' aantasting van het 'twin peaks'-model.

De Wft-delta waar de sectorale Europese richtlijnen uitmonden in de cross-sectorale Wft-wateren ziet er van bovenaf en op het eerste gezicht uit als een imposant wetlandschap, maar eenmaal geland en vervolgens het Wft-landschap doorcrossend blijkt dat de diverse hoofdstromen (Wft), zijrivieren (Besluiten) en kreken (toezichthouderregels en beleidsregels) een gebied zijn geworden dat het risico herbergt dat zonder een duidelijke landschapskaart niet alleen de 'gebruiker' maar ook de wetgever het spoor bijster kan raken en soms ook raakt. Pogingen om alsnog een waterscheiding aan te brengen in de vorm van een herziening van de Wft hebben in een land dat bekend staat om zijn kennis en ervaring met waterwerken, tot nu toe schipbreuk geleden zonder daarvan openlijk kond te doen. Het gezaghebbende college dat de wetgever adviseert - de Raad van State - deed medio 2020 nog een poging om te achterhalen wat de stand van zaken is, nadat al veel eerder door de Raad was gepleit voor een herziening van de opzet van de Wft teneinde de toegankelijkheid te verbeteren en de wet toe- 


\section{Maandblad}

Ondernemingsrecht

komstbestendig te maken. Welnu, een volledige herziening van de Wft levert te veel nadelen op aangezien dit een zeer omvangrijk traject is met een groot en langdurig beslag op wetgevingscapaciteit, de toezichthouders en de financiële sector, en met aanzienlijke kosten voor betrokkenen als gevolg van het proces van aanpassing en overgang, aldus de minister van Financiën. Dit antwoord valt, enigszins oneerbieding uitgedrukt, in de categorie 'verzint eer gij begint'. Immers, dit was bij de enthousiaste start voor een herziening niet alleen te voorzien, maar ook onderkend. Overigens heeft de minister in het midden gelaten of, en zo ja, een gedeeltelijke herziening nog wel ergens op de agenda staat: 'hoop doet leven'.

\section{Er gloort licht aan de horizon}

Weliswaar is nu duidelijk dat een volledige herziening van de cross-sectorale Wft er niet zal komen en het nog maar de vraag is of een gedeeltelijke herziening serieus wordt overwogen, toch zal de Wft in de komende periode aan toegankelijkheid winnen door een afslankoperatie die indirect wordt uitgevoerd door de Europese wetgever. Zoals al opgemerkt kiest de Europese wetgever er de laatste jaren steeds vaker voor om de regelgeving niet in een richtlijn maar zowel op het eerste niveau als op het tweede niveau van regelgeving vast te leggen in verordeningen. Dit heeft inmiddels ook tot gevolg gehad dat bepaalde Wft-bepalingen moesten vervallen. Zo zijn bijna alle bepalingen in Hoofdstuk 5.1 Wft voor het aanbieden van effecten vervallen door de inwerkingtreding van de Prospectusverordening 2017. Datzelfde geldt door de inwerkingtreding van de MAR voor Hoofdstuk 5.4 Wft dat regels bevatte ter voorkoming van marktmisbruik. Hierdoor is de omvang van de Wft én de daarop gebaseerde lagere regelgeving gereduceerd, zij het tot nu toe in bescheiden mate. Dat voor het in Nederland geldende financieel toezichtrecht niet alleen de Wft bepalend is, maar ook het Europese recht is niet nieuw. Nieuw is dat het Europese recht steeds minder terug te vinden is en zal zijn in de cross-sectorale Wft en meer in de sectorale Europese wetgeving telkens wanneer de Europese regulering wordt vormgegeven in rechtsreeks werkende verordeningen. De europeanisering van de materiële regels en de toezichtregels enerzijds en de nationale Wft-regels anderzijds vormen, het is al opgemerkt, communicerende vaten. Gedurende de periode 2009-2021 zijn 23 nieuwe Europese sectorale verordeningen op het eerste niveau van regelgeving met betrekking tot het terrein van de financiële sector vastgesteld en vijf nieuwe sectorale verordeningen voorgesteld hetgeen een gemiddelde is van meer dan één per jaar. Vooral de uitvoering van de actieplannen ter zake van de kapitaalmarktunie is een 'bolwerk' van verordeningen met uitvoeringsopdrachten aan de drie sectorale ESA's. Oudere, reeds in de lidstaten geïmplementeerde, richtlijnen, zoals de Transparantierichtlijn, staan op de nominatie voor een evaluatie. Niet uitgesloten is dat de ingezette lijn om vaker te kiezen voor een verordening dan een richtlijn wordt doorgetrokken. Zo mondde de evaluatie van de Prospectusrichtlijn uit in een Prospectusverordening, de evaluatie van de Richtlijn marktmisbruik en de MiFID I in een duale regeling in de vorm van zowel een nieuwe richtlijn als een ver- ordening. Of de recente introductie van de 'one-in-one-out'-regel (OIOO-beginsel) inhoudend dat elke toename van regeldruk, gemeten in euro's, die wordt veroorzaakt door een nieuw voorstel voor regelgeving, wordt gecompenseerd door een maatregel op hetzelfde terrein die zorgt voor een even grote daling van de regeldruk daadwerkelijk zal worden toegepast, zal moeten blijken.

Ten tijde van de totstandkoming van het ESFS is de vraag aan de orde geweest of het de voorkeur zou hebben om één enkele autoriteit op te richten voor de drie sectoren. Daartoe is toen niet besloten. In plaats daarvan werd gekozen voor het $\mathrm{Ge}$ mengd Comité als forum voor samenwerking tussen de drie ESA's ten behoeve van sectoroverstijgende kwesties, enigszins lijkend op de Raad van Financiële Toezichthouders die in Nederland korte tijd heeft bestaan totdat het functionele cross-sectorale toezichtmodel in de Wft werd ingevoerd. Ook na de evaluatie van het ESFS in 2014 en in een discussienota uit 2017 werd nagedacht om te komen tot één Europese toezichthouder op de kapitaalmarkten. En hoewel deze gedachte nog steeds leeft, zoals in 2020 in het HLF-rapport 'A new Vision for Europe's capital markets', verwacht ik niet dat dit, althans niet op korte termijn, zal leiden tot het samengaan van de drie sectorale ESA's tot één cross-sectorale Europese toezichthouder, maar wellicht wel tot successievelijk drie sectorale Europese toezichthouders. ESMA is reeds aangewezen als Europees toezichthouder op onderdelen van de EMIR, de CRA-verordening, de MiFIR en de Benchmarkverordening. ESMA's rol als Europees toezichthouder zal door de toekomstige Verordening ter zake van Europese groene obligaties worden uitgebreid. De externe entiteiten die de door uitgevende instellingen van groene obligaties met het keurmerk 'EuGB' te verschaffen informatie moeten toetsen, zullen onder rechtstreeks toezicht van ESMA vallen.

Dit alles overziend en afrondend, meen ik dat de huidige cross-sectorale opzet en inrichting van de Wft nog steeds de aansluiting mist met het Europese sectorale model. De gedachte dan wel de wens van de Nederlandse wetgever ten tijde van het opstellen van de Wft was dat ook het Europese recht de sectorale indeling zou gaan verlaten en zou 'overstappen' naar een cross-sectorale opzet. Die gedachte was begin 1999 gestoeld op een succesvol geacht streven van Nederland om in Europees verband de sectoroverschrijdende toezichtdimensie onderwerp van bespreking te maken. Daarvoor pleitte Nederland ook in de Financial Services Policy Group. Dat was met name in het kader om te komen tot een richtlijn over het toezicht op financiële conglomeraten die zich begeven op alle drie sectoren, de latere Fico-richtlijn. De internationale aanzetten tot een op onderdelen sectoroverschrijdende optiek nopen, zo liet de minister toen weten, de sectorale toezichthouders van ons land tot afstemming van hun internationale optreden, vooral waar 'de financiële-sectorintegratie van Nederland internationaal voorop loopt'. Bovendien stelde hij dat Nederland gebaat is 'bij een adequate sectoroverschrijdende aanpak op het internationale plan en daar zelf goed voor moet zijn 


\section{Maandblad}

Ondernemingsrecht

toegerust'. Dat was in feite het startsein om te werken aan een cross-sectorale toezichtwet waaraan - wellicht thans 'contrecoeur' - wordt vastgehouden hoewel de Wft-wetgever thans zal moeten onderkennen dat de aanvankelijke gedachte en vooral de wens van een toekomstig Europees cross-sectoraal toezichtrecht tot nu toe niet is uitgekomen, ook al is er Europese regelgeving aan te wijzen die minder sectoraal en meer cross-sectorale trekken heeft.

De in 2008, een jaar na de inwerkingtreding van de Wft, verschenen nota 'Vertrouwen in wetgeving' bevattend een integraal wetgevingsbeleid dat onder meer uitging van het 'vertrouwen dat de samenleving moet kunnen stellen in de wet en de zorgvuldige uitvoering ervan' schiep hoge verwachtingen, maar de praktijk is, zoals zo vaak, weerbarstig zeker wanneer wordt gekeken naar de ervaringen sindsdien met het financieel toezichtrecht. De Wft zal de meeste van haar huidige regels en uitvoeringsregels moeten inleveren telkens wanneer de desbetreffende materie van in de Wft geïmplementeerde Europese richtlijnen al dan niet na een evaluatie in een verordeningenjas wordt gestoken. Dan zal er ook in de nabije toekomst steeds minder te implementeren zijn in de nationale wetgeving van de lidstaten, derhalve wat Nederland betreft in de Wft. Daar staat tegenover dat de kennis over en de uitleg van het financieel toezichtrecht steeds meer een kwestie is geworden van het op de voet volgen van het Europese toezichtrecht dat de nationale wetgeving van de lidstaten langzaamaan maar gestaag rechtstreeks - zonder implementatieperikelen - 'overneemt'. De sectorale opzet van dat Europese toezichtrecht maakt dat velen zich in de praktijk concentreren op de regelgeving die van toepassing is op een van de drie sectoren. Dat is ook mede de reden geweest om de opzet van 'Koersen door de Wft op het financieel toezicht' in te delen in afzonderlijke sectorale delen maar wel met een grote nadruk op de totstandkoming, inhoud en uitdijing van het Europese toezichtrecht. 